ARTICLE

Received 1 Dec 2016 | Accepted 29 Jun 2017 | Published 22 Aug 2017

DOI: $10.1057 /$ palcomms.2017.77

\title{
Advance directives and knowledge of future selves
}

Christopher Buford ${ }^{1}$

\begin{abstract}
A number of concerns have been raised with respect to advance directives. Advance directives are intended to allow a person who is currently capable of giving informed consent to determine how they are to be treated at a later time at which they are not competent to give such consent. For example, an advance directive such as a living will might specify that should a patient face severe dementia, certain forms of treatment should not be provided if needed to prolong life. Or an individual might fill out a do-not-resuscitate order asking not to be revived in the event of a heart attack. This article discusses three distinct arguments that have been offered against the legitimacy of some or all advance directives. After laying out each argument, focus is given to a potential response to one of the arguments in particular, an argument labelled the "Ignorance Argument". The argument contends that the potential application of any advance directive is plagued by a host of epistemic issues that are serious enough to hamper the very expression of autonomy advance directives are designed to allow for. A possible response to the argument is developed. The response suggests that the argument may place unduly severe constraints on the type of selfknowledge needed to underwrite the expression of a person's autonomy through the creation of an advance directive. The response identifies some connections between the different arguments. An answer is also given to a recent criticism, offered by Eric Vogelstein (2016), which questions the existence of the type of autonomy needed to underwrite advance directives.
\end{abstract}

\footnotetext{
${ }^{1}$ University of Akron, Akron, OH, USA Correspondence: (e-mail: cb72@uakron.edu)
} 


\section{Introduction}

here are a number of assumptions that the legitimacy of a particular application of an advance directive appears to operate under. First, there is the assumption that the author of the advance directive is the same individual as the individual whose treatment (or lack of treatment) is determined by the directive. Second, there is the assumption that the author of the directive possesses the power to extend her autonomy to decisions that concern a future state of herself. It is not surprising that questions have been raised about each of these two assumptions. Regarding the first assumption, some (Dresser and Robertson, 1989; DeGrazia, 1999) have argued that if we assume a Neo-Lockean (Parfit, 1971) theory of personal identity (that is, a theory requiring that there exist psychological relations between $\mathrm{A}$ and $\mathrm{B}$ in order for $\mathrm{A}$ to be the same person as B), then in many of the cases advance directives are intended to cover, the author of the directive no longer exists. ${ }^{1}$ For example, in case of dementia, the psychological connections between the person at the time she authors the advance directive and the individual facing dementia may be so slight as to make it the case that the two are not the same person. And if the author and the future individual are not the same person, the directive cannot be applied. Regarding the second assumption, some (Dresser, 1995; Shiffrin, 2004) have argued that there are significant problems with the claim that the author can extend her autonomy, via what has been labelled precedent autonomy, into the future in the way needed for advance directives to be legitimate. The existence of this type of autonomy appears to entail problematic consequences. In particular, the authority of this type of autonomy would appear to sanction the author condemning a mirthful but incompetent individual to death (see Menzel and Steinbock, 2013 for discussion).

Another potential concern with advance directives is epistemic in nature. Part of the reason I can currently make autonomous decisions is that I have reliable access to my beliefs and desires. Without such access it is hard to see how I could make a truly autonomous decision. Meaningful autonomy arguably requires being able to align one's choices with one's attitudes, desires and values. A third assumption thus tied to the legitimacy of the application of advance directives is that I am not or need not be wholly ignorant of the beliefs and desires of my future self. For without such knowledge, decisions made in the present risk violating the autonomy of my future self. The problem for those who endorse the use of advance directives is that the beliefs and desires of my future self are arguably too distant to ground any exercise of autonomy. As with all cases of possible future selfknowledge, the self I claim to have knowledge of lies in the future. Due to this fact, it is likely that external factors, for example, changes in technology or one's personal relationships, will affect the rational assessment of one's current and future attitudes, often in unpredictable ways (Dresser, 1986). Further, the very nature of the circumstances in which a directive is apt to be applied, entails that one will have undergone what has been labelled (Paul, 2014, 2015) a transformative experience. And this type of experience involves a seemingly unpredictable alteration of attitudes.

Given the assumptions noted above, there emerge three different arguments that can be used to argue against the legitimacy of advance directives; each involving the denial of one of the assumptions noted above. Although the arguments are distinct, we should not overlook the possibility that there are important connections between the arguments. Let us first state each argument in a more perspicuous fashion.

(Identity)

1. An advance directive can only apply to the individual who authored the advance directive.
2. The author of the advance directive is not the same individual as the individual to whom the directive might be applied. (Denial of Assumption 1)

3. So, the advance directive cannot be legitimately applied.

Critical discussion of (Identity) has seen objections to both premises.

\section{(Autonomy)}

1. An advance directive can only apply to an individual if she has made an autonomous choice to accept the treatment (or nontreatment) recommended by the directive. (Denial of Assumption 2)

2. The individual to whom the directive might be applied lacks the capacity to make such an autonomous choice.

3. So, the advance directive cannot be legitimately applied.

Most who have objected to (Autonomy) have focused on the first premise.

\section{(Ignorance)}

1. An advance directive can only apply to an individual if, when authoring the directive, she possesses knowledge of the incompetent individual's beliefs and desires sufficient to allow for an autonomous decision.

2. The author the advance directive lacks knowledge sufficient to ground such a decision. (Denial of Assumption 3)

3. So, the advance directive cannot be legitimately applied.

(Ignorance) will be discussed in detail shortly. The rest of the current section examines each of the first two arguments in detail. It is hoped this will prove beneficial for the evaluation of (Ignorance) to come.

One way to challenge (Identity) is to point out that there are theories of personal identity over time that allow for identity of author and the later individual. The claim that the author is not the same individual as the individual whose treatment might be guided by the advance directive can be supported by appeal to a Neo-Lockean account of personal identity over time. According to such an account, there must exist some form of psychological connection between an individual at some time and an individual at a later time if there is to be one individual throughout (Parfit, 1971). One competitor to a Neo-Lockean account is Animalism. Animalism is the claim that each human person is numerically identical to a human animal (Olson, 1997). Thus, wherever my animal goes, I go since I am identical to that animal. Further, since this animal does not have psychological persistence conditions, I do not. Adopting Animalism would thus allow us to reject the second premise of (Identity). If this theory is correct, then it is false that the author of the advance directive no longer exists. Some (DeGrazia, 2005) have taken this route in an effort to respond to (Identity).

One might also object to the first premise. Some (Buchanan, 1988; Edwards, 2011) have suggested that the lack of identity between the author of the directive and the individual who apparently needs the directive does not entail that the advance directive in question lacks force. In fact, some proponents of psychological accounts of personal identity over time like Parfit have argued that identity is not in fact what matters, where a relation matters if it grounds the legitimacy of attitudes such as anticipation, regret and responsibility. Parfit argues in part for this claim by employing a fission scenario involving the successful transplantation of each of your cerebral hemispheres to distinct bodies. Parfit argues that though you may not survive such a 
procedure, it is clear that the relation or relations that ground what matters obtain. As evidence of this, consider whether it would be rational to anticipate the joy or pain felt by one of the fission products. Of course, we would still be left without an account of how it is that an advance directive authored by me could apply to a distinct individual. Further, some (Buford, 2008; Buford, 2014) have questioned the viability of accounts that attempt to reject the claim that identity is necessary for the legitimate employment of an advance directive. The main worry is that no other relation is up to the task of grounding the legitimacy of advance directives in the very cases the directive is created to address; one of the obvious replacement candidates, psychological continuity, is absent in some of the cases (for example, persistent vegetative state scenarios) where advance directives are often deemed applicable.

Our brief examination of the issues surrounding (Identity) suggests a possible response to (Ignorance). Suppose we grant that identity between the author of the directive and the individual to whom the directive is to apply is required for an advance directive to have authority. Further, suppose that a strong Neo-Lockean theory, according to which direct psychological connections (for example, persistence of belief; memorial representation of past experience; action based on previous intention) are required for personal identity over time, is true. These two assumptions entail that whenever an advance directive has authority, that is, when there is sameness of person, the author will be positioned to have knowledge of her future self. Since direct psychological connections are required on such an account of our identity over time, this future individual will necessarily have at least some of the same beliefs or intentions as the author of the directive. Further, as noted by Marya Schectman (2015), direct connections of the sort stressed by Locke seem especially relevant to the grounding of facts about moral responsibility.

Locke provides us with cases in which we are supposed to make judgments about accountability; where these apply we can conclude that we have the same person (that is, the person with the cobbler's body and prince's consciousness is responsible for the prince's earlier actions so is the same person as the prince) and where they do not apply we can conclude there is not (that is, there person with the prince's body and cobbler's consciousness is not responsible for the prince's earlier actions and so is not the prince). It would thus seem that the limits of the person should coincide with the limits of the justified attributions of responsibility. (Schectman, 75)

A strong Neo-Lockean account thus seems to provide a way to help resolve the concerns raised by (Ignorance) and to help explain the legitimacy of advance directives by tying their application to the very same relationship that grounds the legitimacy of attributions of moral responsibility.

There are though numerous problems facing this particular attempt to answer (Ignorance). An account of personal identity over time requiring psychological connections of this sort is suspect. Most of us cannot remember our tenth birthday yet still believe that we were in fact present to celebrate the event. However, if direct psychological connections are required, then the lack of any direct belief, memory, or intention links between $\mathrm{A}$ and $\mathrm{B}$ would entail that $\mathrm{A}$ and $\mathrm{B}$ are not the same person. In fact, most contemporary psychological theorists (Parfit, 1971; Shoemaker, 1984) deny that direct psychological connections are necessary for sameness of person instead opting for the requirement that $\mathrm{A}$ and $\mathrm{B}$ be psychologically continuous; psychological continuity between $A$ and $B$ only requires that $A$ and $B$ are connected by overlapping chains of direct psychological connections. Also, the proposed solution to (Ignorance) risks giving up on the legitimacy of most advance directives. Individuals who are suffering from dementia or who exist in a persistent vegetative state are not psychological connected directly to the author of the directive. If the first premise of (Identity) is correct, however, the numerical distinctness of author and potential beneficiary of the advance directive is incompatible with the legitimate utilization of an advance directive.

Let us now turn to examining any potential connections between (Ignorance) and (Autonomy). The state of the dialectic with respect to (Autonomy) is less complicated given that rejecting the second premise seems implausible. In the cases under consideration, the individual is described so as to almost by definition rule out currently having the capacity to make an autonomous decision. Thus, it is the first premise that has raised concerns. In response, it has been suggested that persons possess precedent autonomy, which is the power not just to decide how to be treated now, but also how to be treated in the future. The existence of precedent autonomy would then serve to underwrite the legitimacy of advance directives.

To help us see the relationship between (Ignorance) and (Autonomy) it will help to first to investigate reasons that might be given in favour of premise two of (Ignorance). One way to argue for the premise is to rely on LA Paul's $(2014,2015)$ notion of an epistemically transformative experience. A transformative experience is an experience that induces a radical change in the subject's beliefs, desires, and overall cognitive life. Paul gives as an example the transformative experience of having a child. Having a child often triggers a drastic shift in one's attitudes and values. Further, some experiences are epistemically transformative in that before undergoing the experience, the subject does not know what type of cognitive transformation will take place as a result of undergoing the experience. Paul uses the existence of epistemically transformative experiences to argue against contemporary approaches to rational decision making. She claims that such approaches requires the rational subject to assess the value (and likelihood) of each possible outcome when deciding whether to undergo an epistemically transformative experience. The problem, according to Paul, is that epistemically transformative experiences are by their very nature, resistant to this methodology. For how can one assess the value of each outcome, when the value of that outcome depends on a cognitive life that is beyond one's ken?

The experience of undergoing severe dementia appears to qualify as a transformative, as well as an epistemically transformative, experience. It seems true both that one's beliefs, desires, and so on... will change radically and that having never undergone such a transformation, one is unlikely to have knowledge of how exactly one will be changed by the experience. If making a rational autonomous decision requires having such knowledge, and such knowledge is impossible in the cases under consideration, then advance directives cannot be employed. An important assumption in this defense of the second premise is that to have knowledge sufficient to ground an autonomous decision, one's self-knowledge must extend into the future (that is, I must now have knowledge of how my future self will be). However, if precedent autonomy does in fact exist, then it is not clear that this assumption is correct, especially when we consider cases where the future self is incompetent. Consider the following thought experiment.

Regan strongly identifies with the animal rights movement. She believes that animals have the right not to be exploited and used for resources. She learns that she has a life threatening disease. However, the disease can be cured by taking a pill. The pill will render her the mental equivalent of a two year old, though only for a short duration. Most 
surprisingly, the pill will give her an overwhelmingly strong desire to eat meat.

Imagine that Regan tells her physician that she is willing to have the procedure only on the condition that she not be allowed to have any meat. Were I the physician, I would have no qualms with agreeing to her condition even though this would mean ensuring that the later desires of her future self would be frustrated. It is true that the physician might agree to save Regan's life, but if this were the only factor, then the physician could "agree" and then not tell Regan about feeding her later self a nice steak. We can even assume that taking the pill will induce in Regan a transformative experience since she has never liked the thought of eating meat and has never tasted a steak. This though seems unlikely to weaken the intuition supporting the decision to abide by Regan's wish to have the desire of her later self to unfulfilled.

A potential response to the preceding argument is to point to a disanalogy between Regan and the individual to whom the directive may or may not apply. Denying Regan a meal will not cause significant harm but allowing an individual to die will. The objection is thus that our intuitions concerning the former case need not necessarily carry over to the latter. This is an interesting objection and certainly one worth taking seriously. However, it is not clear to me that the disanalogy is persuasive. To see this, consider Regan's case but with one added detail.

Regan strongly identifies with the animal rights movement. She believes that animals have the right not to be exploited and used for resources. She learns that she has a life threatening disease. However, the disease can be cured by taking pill. The pill will render her the mental equivalent of a two year old, though only for a short duration. Most surprisingly, the pill will give her an overwhelmingly strong desire to eat meat. This desire will be accompanied with a moderate level of pain. Pain that will not subside until either the desire is satisfied or the treatment runs its course.

Clearly denying Regan meat will either cause or at least fail to prevent significant harm to Regan. The key question is whether the addition of the harm to the scenario is sufficient to justify overriding Regan's earlier expression of autonomy. My claim here is not that it obviously is not, but instead that adding a pain component to the thought experiment does not clearly rule out abiding by Regan's request. We can even imagine that she is well aware that she will be in pain tomorrow yet still expresses a desire to be denied what she will tomorrow desire deeply. ${ }^{2}$

The case of Regan is similar to a case offered by Dworkin. Dworkin (1993) discusses the case of a Jehovah's Witness who needs a blood transfusion and is temporarily incompetent. We are to further imagine that this individual demands while incompetent the transfusion though this goes against religious principles affirmed while the individual was competent. Here, Dworkin feels it is the past desires that need to be respected and respecting these desires is to allow for the expression of precedent autonomy. Eric Vogelstein (2016) is skeptical.

The problem with Dworkin's claim is that in ordinary cases of temporary incompetence it is the case that the patient maintains the desire in question...After all, what other explanation is there for the fact that the patient does possess that desire after regaining competence? The way to make sense of this kind of case is not by supposing that the person genuinely loses the desire not to be transfused and then mysteriously reacquires the very same competence; rather, it is by supposing that the person has the desire all along. Here it is helpful to distinguish desires in their dispositional and occurrent forms. (Vogelstein, 15)

Given that people go through life gaining and losing the same desire constantly, the claim that the same desire must have persisted cannot be the only explanation. Further, the appeal to the distinction between occurrent and dispositional desires does not clearly support Vogelstein's case. An example of a dispositional desire would be my desire to go to Hawaii. I am not acting on this desire at the moment, but if you were to present me with an opportunity to go (for example, plane tickets, condo in Maui, and so on...), I would act on my desire. My desire to complete this paper is though occurrent; the behaviour associated with this desire is not merely dispositional; I am acting on the desire by putting words on the page.

I do not wish to cast doubt on the possibility of different types of desires. I also grant that there is a sense in which Regan is disposed to desire that she not eat meat. However, it does not necessarily follow that she does in fact desire, even dispositionally, to not eat meat. Instead, she seems more like the child who is disposed to desire a particular food that she has never tasted. She will desire it in the future, but I do not think we should say she desires it now. Similarly, Regan, once the medication wears off, will once again desire to not eat meat but she does not desire that now. Finally, Vogelstein (15) offers as an example of a dispositional desire the desires of an individual who is asleep. It does seem correct that I can still desire to go on vacation even if I am asleep. Yet part of what makes this a dispositional desire is presumably what when I am awake, I will act in ways that express this desire. I might save up money for a trip or investigate potential destinations. Regan on the other hand currently exhibits no behaviour that suggests a desire not to eat meat and unlike the individual that is asleep, Regan is currently acting and acting in ways that appear inconsistent with a dispositional desire to not eat meat. For example, if we ask her if she wants meat, she will say yes. And if we place meat in front of her, she will reach for it. We do know that in the near future, she will no longer be so disposed and will in fact be disposed to act in ways consistent with being a vegetarian. Thus, she is disposed to desire to refrain from eating meat in the sense that in the near future she will acquire the dispositional desire to so refrain. But this is not equivalent to actually possessing a dispositional or occurent desire to refrain from eating meat. ${ }^{3}$

If we do not possess precedent autonomy, then the question of whether we can have sufficient knowledge of our future selves to ground the application of an advance directive loses much of its interest. Thus, we should look at one recent challenge to the possibility of precedent autonomy. Vogelstein (2016) asks us to consider the following case, a case he claims to be analogous to many of those offered in debates concerning precedent autonomy.

On Monday, Jim purchased a new car. Jim has selected a special colour for his car: blue. Jim has selected this colour not simply because he enjoys the way blue looks, but also because he attaches deep significance to the colour. For Jim, the colour blue has deep symbolic value; blue exemplifies to Jim all that is good and holy. But the car that Jim wants does no usually come in blue, so it must be painted specially for Jim (at no extra cost), which will happen on Wednesday.

On Tuesday, however, Jim suffers from a very rare illness that permanently causes full colour-blindness and permanently robs a person of all colour-concepts as well as any colour-memories and memories specifically associated with 
particular colours. Thus, on Tuesday, Jim has no idea what blue is, or what it would be to have a blue car, and thus no longer values the colour blue, nor desires that his car be blue.

On Tuesday night, while Jim is in the hospital and is incapacitated, the car dealership call Jim's wife, Anne, to confirm that Jim want the special paint job on his new car; furthermore, if she does not confirm at that time, the opportunity for the special paint job will be lost. Anne knows of Jim's condition, and wonders whether she is morally required to opt for the blue paint. (Vogelstein, 8-9)

Vogelstein ultimately concludes that because Anne need not opt for the blue paint, there is little to the notion of precedent autonomy since it assumes a role for past desires of individuals. Yet in this case, Anne need not feel moved to opt for the blue paint due to Jim's earlier, but no longer possessed desire.

One important difference between the case of Jim and that of individuals who have authored advance directives concerns the nature of the relevant property that is the object of desire. Dworkin (1993) suggests that countenancing precedent autonomy is required to protect critical interests of individuals. Such interests include the integrity of the individual. It is thus of little wonder that the case of Jim and Anne fails to illicit any immediate intuitions respecting the value of precedent autonomy; for it is hard to imagine how the colour of Jim's car, especially given the dearth of details given in the scenario offered by Vogelstein, is tied to Jim's critical interests and integrity. By changing the details of the scenario, we can make the change more relevant to Jim's critical interests.

On Monday, Jim purchased a new car. Jim has selected a special colour for his car: blue. Jim has selected this colour not simply because he enjoys the way blue looks, but also because he attaches deep significance to the colour. For Jim, the colour blue has deep symbolic value; Jim served in the navy during the war and has always identified a particular shade blue with his service and the service of his fellow soldier. Jim promised himself that he would always drive a car of this colour to honor those who gave their life in the line of duty. The colour thus exemplifies to Jim all that is good and holy. But the car that Jim wants does no usually come in blue, so it must be painted specially for Jim (at no extra cost), which will happen on Wednesday.

On Tuesday, however, Jim suffers from a very rare illness that permanently causes full colour-blindness and permanently robs a person of all colour-concepts as well as any colour-memories and memories specifically associated with particular colours. Thus, on Tuesday, Jim has no idea what blue is, or what it would be to have a blue car, and thus no longer values the colour blue, nor desires that his car be blue.

On Tuesday night, while Jim is in the hospital and is incapacitated, the car dealership call Jim's wife, Anne, to confirm that Jim want the special paint job on his new car; furthermore, if she does not confirm at that time, the opportunity for the special paint job will be lost. Anne knows of Jim's condition, and wonders whether she is morally required to opt for the blue paint.

I submit that at the very least, the intuition that is permissible for Anne to turn down the special paint job is less forceful in this case than in the less specific version offered by Vogelstein. And that the reason this is so is due to the relationship between the property desired and Jim's critical interests.
The preceding discussion brings forth a connection between two of the arguments stated above, (Autonomy) and (Ignorance). One response to the former argument is to invoke the power of precedent autonomy, the power to extend one's autonomy into the future. However, if we do have such a power, cases like those of Regan discussed above, indicate that legitimate expression of this type of autonomy does not require that we have the same type of self-knowledge we typically take ourselves to have of our current selves. Yet this is the very assumption that functions as a key premise in (Ignorance). Thus, one satisfied with the appeal to precedent autonomy as a proper response to (Autonomy) should feel considerably less threatened by the epistemic issues raised by (Ignorance).

The knowledge that we often have of our current mental lives is often thought to be grounded in introspection. Self-knowledge on this model is grounded in direct awareness of one's own pre-existing mental states. However, there may be room for a different route to self-knowledge. Here is Richard Moran (2001) discussing a path to self-knowledge that leans heavily on selfinterpretation.

Of the two versions of "self-constitution" involving logical sufficiency, the more radical one claims that at least for a certain range of cases, the person's own interpretation of his state suffices for its being that very way. On such a view, interpreting myself as, say, ambivalent, mistrustful, or ill at ease makes it the case that I am correctly characterized in those terms. In cases like these, we may think that "thinking makes it so" because there's simply nothing to choose between, say, taking oneself to be ill at ease and really being so. (Moran, 44)

While there are differences between the cases Moran notes, which focus on knowledge of one's current mental states, and cases involving possible knowledge of a compromised future self, there may be important similarities. Perhaps I know what my future self will want or value in virtue of expressing such attitudes now. That is, since I am now a person, capable of forming the higher-order desires needed to express such attitudes, and my future-self will not be in a position to express or form these attitudes, my expression of certain values makes it the case that my future self has these values as well. And this also makes it quite easy for me to know what those values will be since it is my current act of self-interpretation that makes it so. And as is suggested above, the very nature of precedent autonomy may require that this picture of the relationship between selfknowledge and future selves be viable, especially if we insist that some type of self-knowledge is needed for the performance of truly autonomous actions.

\section{Notes}

1 Locke is often interpreted as suggesting that $\mathrm{A}$ at $\mathrm{t}$ is the same person as $\mathrm{B}$ at $\mathrm{t}^{\prime}$, where $t^{\prime}<t$, only if A can remember B's experiences. Most contemporary theorists influenced by Locke do not accept this memory-based criterion. Instead, various other psychological relations are suggested as constitutive of personal identity over time.

2 Another worry is that the intuition to accede to competent Regan's wishes is bolstered by one's moral qualms with meat eating. Suppose instead that Regan is a meat-eater who will acquire an intense desire for seaweed. I agree that intuitions may be weaker here, but now the case resembles the case of Jim discussed in the text for we have a hard time identifying with Regan's values here. Thanks to an anonymous referee for raising this concern.

3 It is true that in the type of cases under discussion, the incompetence is temporary. However, the aim of the line of argumentation is to suggest that the current dispositions of the incompetent person need not necessarily be a guide to how we ought to treat the person. We could change the example to allow that Regan will not regain competence, but this seems to just be an advance directive case. 


\section{References}

Buchanan AE (1988) Advance directives and the personal identity problem. Philosophy and Public Affairs; 17 (4): 277-302.

Buford C (2014) Descendants and advance directives. Monash Bioethics Review; 34 (32): 217-231.

Buford C (2008) Advancing an advance directive debate. Bioethics; 22 (8): 423-430.

DeGrazia D (2005) Human Identity and Bioethics. Cambridge University Press: Cambridge.

DeGrazia D (1999) Advance directives, dementia and 'the Someone else problem'. Bioethics; 13 (5): 373-391.

Dresser R (1995) Dworkin on dementia: Elegant theory, questionable policy. Hastings Center Report; 25 (6): 32-38.

Dresser R (1986) Life, death, and incompetent patients: Conceptual infirmities and hidden values in the law. Arizona Law Review; 28 (3): 373-405.

Dresser R and Robertson J (1989) Quality of life and non-treatment decisions for incompetent patients: A critique of the orthodox approach. Law, Medicine \& Health Care; 17 (3): 234-244.

Dworkin R (1993) Life's Dominion. Alfred A. Knopf, Inc.: New York, NY.

Edwards C (2011) Respect for other selves. Kennedy Institute of Ethics; 21 (4): 349-378.

Menzel P and Steinbock B (2013) Advance directives, dementia, and physicianassisted death. Journal of Law, Medicine \& Ethics; 41 (2): 484-500.

Moran R (2001) Authority and Estrangement: An Essay on Self-Knowledge. Princeton University Press: Princeton, NJ.

Olson E (1997) The Human Animal. Personal Identity Without Psychology. Oxford University Press: Oxford.

Parfit D (1971) Personal identity. The Philosophical Review; 80 (1): 3-27.

Paul LA (2015) What you can't expect when you're expecting. Res Philosophica; 92 (2): $1-14$.

Paul LA (2014) Transformative Experience. Oxford University Press: Oxford.

Schectman M (2015) Staying Alive: Personal Identity, Practical Concerns, and the Unity of a Life. Oxford University Press: Oxford.
Shiffrin S (2004) Ronald Dworkin and His Critics. In Burley J (ed). Autonomy, Beneficience, and the Permanently Demented. Malden, MA: Blackwell Publishers, pp 195-217.

Shoemaker S (1984) Personal Identity: A Materialist's Account in Shoemaker and Swinburne, Personal Identity. Blackwell: Oxford.

Vogelstein E (2016) Autonomy and the moral authority of advance directives. Journal of Medicine and Philosophy. doi:10.1093/jmp/jhw019.

\section{Data availability}

Data sharing is not applicable to this paper as no datasets were analysed or generated.

\section{Additional information}

Competing interests: The author declares that there are no competing financial interests.

Reprints and permission information is available at http://www.palgrave-journals.com/ pal/authors/rights_and_permissions.html

How to cite this article: Buford C (2017) Advance directives and knowledge of future selves. Palgrave Communications. 3:17077 doi: 10.1057/palcomms.2017.77.

Publisher's note: Springer Nature remains neutral with regard to jurisdictional claims in published maps and institutional affiliations.

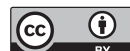

This work is licensed under a Creative Commons Attribution 4.0 International License. The images or other third party material in this article are included in the article's Creative Commons license, unless indicated otherwise in the credit line; if the material is not included under the Creative Commons license, users will need to obtain permission from the license holder to reproduce the material. To view a copy of this license, visit http://creativecommons.org/licenses/by/4.0/

(C) The Author(s) 2017 